\title{
Technology Corner: Visualising Forensic Data: Evidence Guidelines (Part 2)
}

Damian Schofield

State University of New York

Ken Fowle

Edith Cowan University

Follow this and additional works at: https://commons.erau.edu/jdfsl

Part of the Computer Engineering Commons, Computer Law Commons, Electrical and Computer Engineering Commons, Forensic Science and Technology Commons, and the Information Security Commons

\section{Recommended Citation}

Schofield, Damian and Fowle, Ken (2013) "Technology Corner: Visualising Forensic Data: Evidence Guidelines (Part 2)," Journal of Digital Forensics, Security and Law. Vol. 8 : No. 2 , Article 4.

DOI: https://doi.org/10.15394/jdfsl.2013.1145

Available at: https://commons.erau.edu/jdfsl/vol8/iss2/4

This Article is brought to you for free and open access by

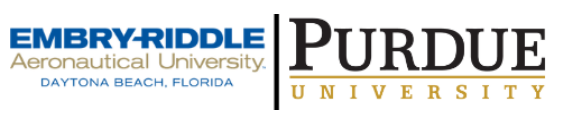
the Journals at Scholarly Commons. It has been accepted for inclusion in Journal of Digital Forensics, Security and Law by an authorized administrator of Scholarly Commons. For more information, please contact commons@erau.edu.

(c)ADFSL 


\title{
TECHNOLOGY CORNER VISUALISING FORENSIC DATA: EVIDENCE GUIDELINES (PART 2)
}

\author{
Damian Schofield \\ State University of New York \\ Department of Computer Science \\ schofield@cs.oswego.edu \\ +1(410) 5043178 \\ Ken Fowle \\ Edith Cowan University \\ School of Computer and Security Science \\ k.fowle@ecu.edu.au \\ +61(8) 93706013
}

\begin{abstract}
Visualisation is becoming increasingly important for understanding information, such as investigative data (for example: computing, medical and crime scene evidence) and analysis (for example, network capability assessment, data file reconstruction and planning scenarios). Investigative data visualisation is used to reconstruct a scene or item and is used to assist the viewer (who may well be a member of the general public with little or no understanding of the subject matter) to understand what is being presented. Analysis visualisations, on the other hand, are usually developed to review data, information and assess competing scenario hypotheses for those who usually have an understanding of the subject matter.

Courtroom environments are morphing into cinematic display environments, the media consumed by an audience who are increasingly visually literate and media savvy (Heintz, 2002). There are a number of fundamental implications inherent in the shift from oral to visual mediation and a number of facets of this modern evidence presentation technology needs to be investigated and analysed. One of the primary issues of visualisation is that no matter how coherent the data, there will always be conjecture and debate as to how the information is/has-been visualised and, is it presented in an acceptable and meaningful way.

This paper presents a range of examples of where forensic data has been visualised using various techniques and technology, the paper then examines
\end{abstract}


aspects of the visual courtroom evidence presented and discusses some of the benefits and potential problems of implementing this technology. This paper is part two of a two-part series that aims to describe the use of, and provide guidelines for, the use of graphical displays in courtrooms.

Keywords: Visualization, Evidence, Reconstruction, Digital Forensics, Computer Graphics, Forensic Animation, Guidelines.

\title{
1. INTRODUCTION
}

Part one of this two part series discussed the way digital visual evidence presentation systems (including digital displays, computer-generated graphical presentations and three-dimension simulations) have already been used in many jurisdictions. Within the realms of forensic science, the use of new technologies in order to gather, analyse and present evidence is of the utmost importance in the modern world. Many forensic disciplines are facing an evergrowing amount of data and information that needs to be analysed, processed, and communicated. Those who have to look at, browse, or understand the data (judges, lawyers, jurors, etc.) need ways to display relevant information graphically to assist in understanding the data, analysing it, and remembering parts of it.

The ability of a computer to create synthetic copies of an event or issue (whether as a static image, a plan or schematic, a computer animation or a virtual reality simulation) may provide an opportunity to enhance the viewer's current understanding. Modern systems for creating visualisations have evolved to the extent that non-experts can create meaningful representations of their data. However, the process is still not easy enough, mainly because the visual effects of processing, realising and rendering data are not wellunderstood by the user, and the mechanisms used to create visualisations can be a largely ad hoc process (Rogowitz and Treinish, 2006).

\section{ISSUES ARISING FROM THE USE OF FORENSIC ANIMATIONS AND VIRTUAL SIMULATIONS}

\begin{abstract}
...people who watch such television programs [CSI] regularly expect better science than what they are often presented with in courts ... In other words, CSI leads viewers to expect hightech science and something more than the intuition of the witness, so that when in court they are presented with much lower-tech science and the witness's subjective judgment, they are likely to find it less convincing than do non-CSI viewers (Schweitzer and Saks, 2007).
\end{abstract}

Most people would be positive about the benefits of the forensic animations and virtual simulations used in the cases which are described in the following 
section and it is often easy to understand how the visuals helped the jury to assess the burden of guilt. However, there are a number of issues and questions that appear when such reconstructions are closely examined. These will be discussed in further detail, with examples, in the following sections.

\subsection{Viewpoint}

The first issue is how to correlate the viewpoint of a witness in a "virtual" environment with the view from their physical position at the scene. For example, compare the "physical world" view of the driver of the vehicle involved in a road traffic accident (such as the one shown in Figure 1) with the field of view of a camera in a virtual reconstruction. In some cases, it may be possible to show views of the incident from the viewpoints of many different parties (victims, witnesses etc.) involved (Noond et al., 2002).

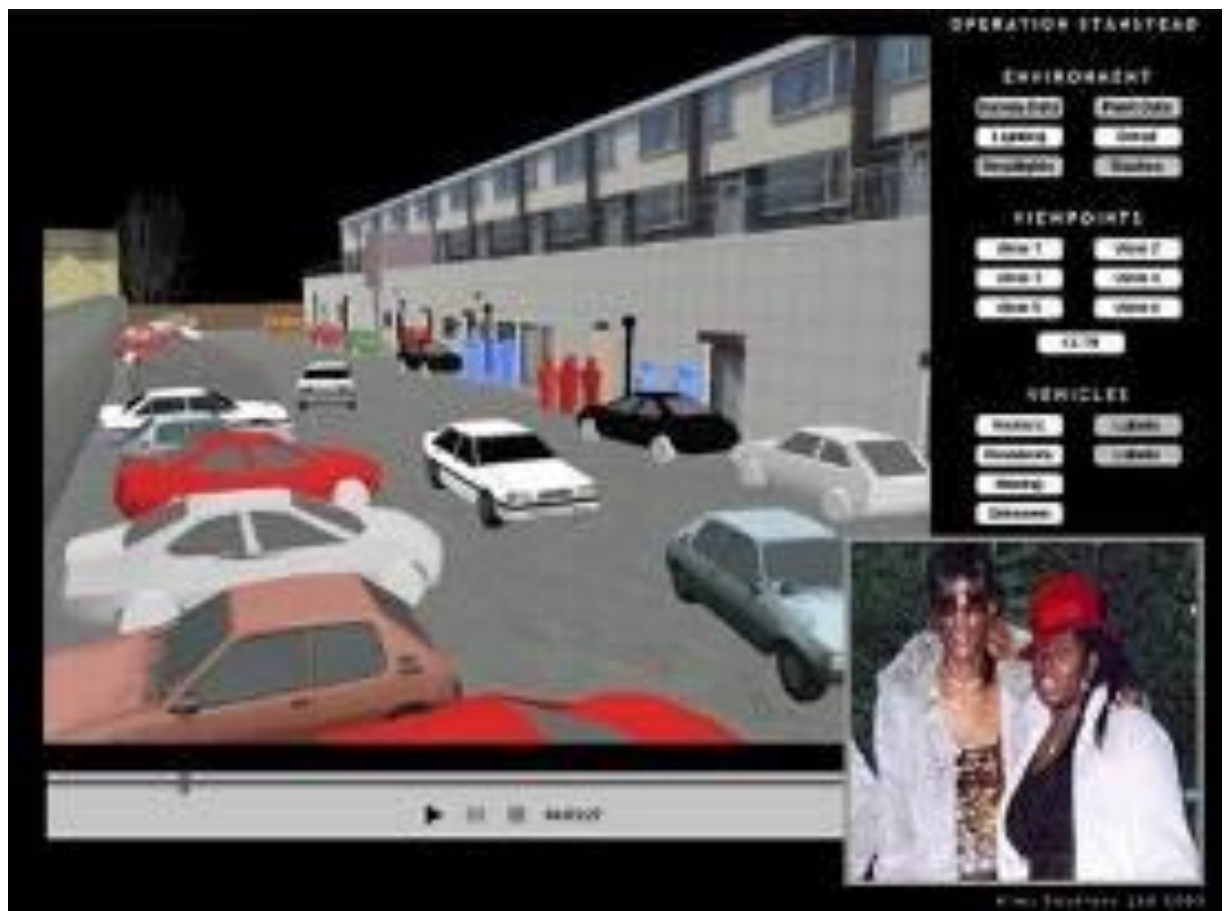

Figure 1 Image from a Virtual Simulation of a Drive By Shooting

As an example of the importance of viewpoint in a virtual reconstruction, consider the high profile investigation of a drive by shooting in Birmingham, UK. The police commissioned a large-scale virtual reconstruction to simulate the events of the evening of the incident. Two young women died when they were sprayed with bullets from a sub-machinegun as they stood with other revellers outside the back entrance of a hairdressing salon where they had been attending a New Year party. The dead girls, both aged 18, were caught in the crossfire when a gun battle broke out between two rival gangs (Britten, 2003). 
An interactive crime scene briefing tool was created (Figure 2), with all people and vehicles involved represented in the virtual environment (over sixty moving objects) over a two hour time window. Objects were positioned based on CCTV footage, physical evidence recovered from the scene and witness testimony. The use of a real-time graphics engine allowed the user to view the crime scene and event chronology in an interactive way, updating the virtual evidence as and when new information came to light and to view the scene from many different perspectives (Schofield, 2007; Schofield and Mason, 2012). The final version of this briefing tool was then used in court to aid in the conviction of four men for the shootings (BBC News, 2005).
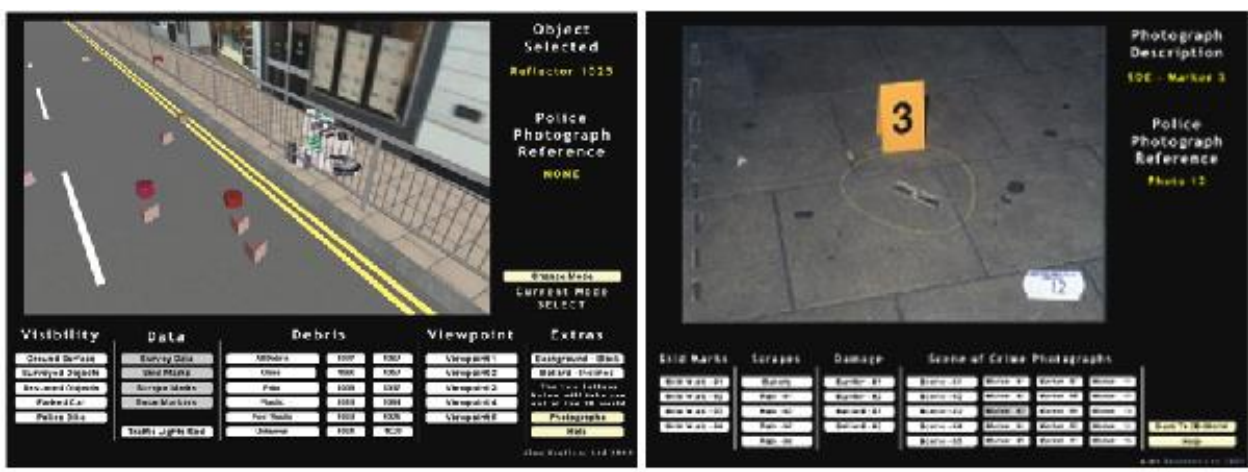

Figure 2 Image from a Virtual Simulation of the Vehicle Debris at the Murder Scene

Popular computer game titles provide a good example of distinct viewing configurations through various game-playing styles. Unreal Tournament ${ }^{\circledR}$ belongs to the First Person Shooter (FPS) genre, distinguished by a first person perspective (egocentric) that renders the game world from the visual perspective of the player character. Grand Theft Auto® is an example of a Third Person Shooter (TPS, a genre of video game in which an avatar of the player character is seen at a distance from a number of different possible perspective angles (exocentric).

In any forensic reconstruction (as in any computer game), the choice of the viewing perspective may have significant effect on the way an image is interpreted by the viewer. Changing the viewing perspective can potentially alter which "character" in an evidence presentation a viewer identifies with, or aligns themselves with (Bryce and Rutter, 2002). Images rendered to the screen may seem objective to the viewer, because they "appear" not to be operated by human beings who by definition have a subjective position. However, these cameras have a point of view that engages the viewer in familiar ways. The viewer becomes the driver, or the victim, or the witness; observing from inside the scene and every aspect of the way the images are presented on the screen can evoke a response (Spielsel and Feigenson, 2009). 
The reconstruction engineers who build these virtual crime scenes need to study film-making techniques for two reasons. Firstly, to potentially achieve the same effects as a film-maker; perhaps getting the viewer to emotively identify with a particular character in a reconstruction to enhance the power of the message. More importantly, an animator or reconstruction engineer may wish to "reverse engineer" these effects and potentially to remove the emotive content to provide an objective, understandable view of a data set, with no distracting emotive attachment. An awareness of the ways the viewer can be manipulated (for example through the use of egocentric and exocentric viewpoints) is essential.

\subsection{Correlating Location}

There is also an issue regarding the correlation of the locations of witnesses when viewed in a three-dimensional video game environment, in comparison to their actual position at the scene. It is a reasonable assumption to make that most people would be better able to correlate their actual spatial location from a three-dimensional "virtual" simulation, than they might be able to on a twodimensional plan or map.

As demonstrated earlier a crime scene sketch and surveys of the crime scene are performed, but when the information is to be presented in a courtroom the crude sketch (which remains as original evidence) is often transformed into a computer-generated graphical image (Figure 3 ) that is used to describe to the court what happened, specifically the spatial location of people and objects at particular moments in time during the event or incident chronology. The primary presentation format is that of the overhead two-dimension plan, allowing witnesses to position and orientate their testimony relative to this graphical construct.

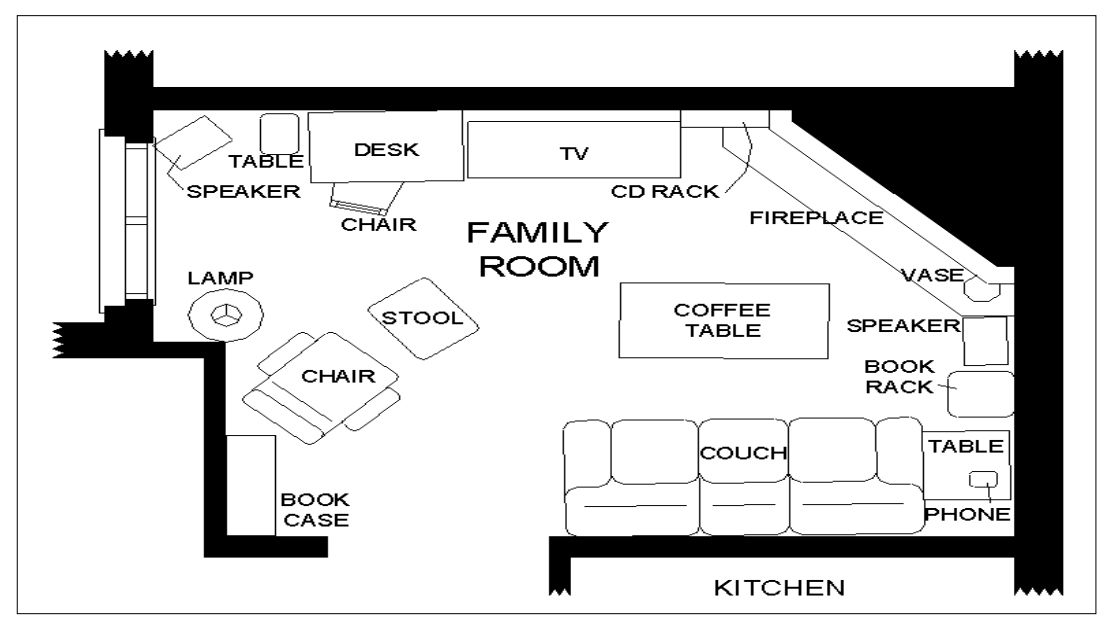

Figure 3 Computer Drafted Crime Scene Plan 
(Courtesy of Mr. G. Schofield, Toronto Police)

It is interesting to note that research has shown that a significant proportion of the general public has problems relating and correlating two-dimensional (e.g., maps and plans) and three-dimensional (e.g., real and virtual) spatial information (Schnabel and Kvan, 2003). In practice, this means that some witnesses may find it easier to their physical position by referring to locate a virtual environment (relating physical three-dimensions to "virtual" three dimensions) rather than on a two-dimensional plan or map of the scene of the incident (Schofield, 2009).

What this means in practice in a typical courtroom scenario is that a number of witnesses may find it easier to position and orientate themselves relative to the real world within a virtual environment (relating "real" three-dimensions to "virtual" three-dimensions) rather than on a two-dimensional plan of the incident scene.

One of the main advantages of the use of an interactive virtual simulation (such as those shown in Figures 1 and 2) over forensic animations (such as the one shown in Figures 4 and 5) is the ability to dynamically control the virtual camera movement within the environment and what this means, in a courtroom setting, is that the user can "interactively" potentially adjust the view of the digital evidence-for example, a witness could move a camera around until the virtual view matches their memory of their view of the incident.

However, it should be appreciated that the ways in which humans position themselves and correlate spatial information between three-dimensional views of virtual and real worlds are by no means fully understood (Ware and Osborne, 1990).

\subsection{Realism}

Figures 4 and 5 are taken from a virtual reconstruction created for the Independent Police Complaints Commission (IPCC) in the UK. This reconstruction related to the fatal shooting of a civilian by police armed response unit in 2005 (Schofield, 2007). The images in Figure 4 demonstrate the level of photorealism it is possible to achieve using modern computer games development software. The image on the left of Figure 4 is a photograph of the exterior of the building where the shooting incident occurred, the image to the right shows the virtual reconstruction of the building environment. It should be noted that this three-dimensional computer model of the house was built in approximately four hours. As software and technology develops, the time to build three-dimension models and program dynamic interaction in these virtual worlds is continually reducing (Wilson et al., 2002). 


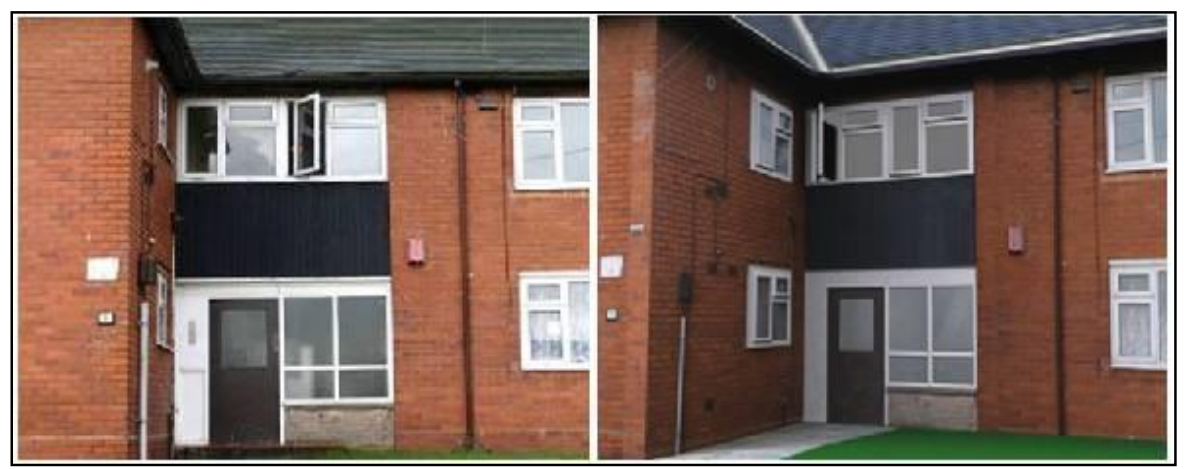

Figure 4 A Photograph and an Image from a Forensic Animation of a Crime Scene

This particular case involved matching a possible bullet trajectory from the police marksman outside the front of the building to the victim, who was stood at a first floor window. To do this a transparent mannequin was used allowing the bullet trajectory (shown in the images in Figure 5) to be visible throughout the animation.

This example demonstrates how it is now possible to attain photorealistic representations within the virtual environments. The virtual reconstruction shown in Figures 4 and 5 demonstrates how objects in the simulation could be modelled with varying degrees of accuracy to explain and visualise the certainty/believability/veracity of the information related to that object.

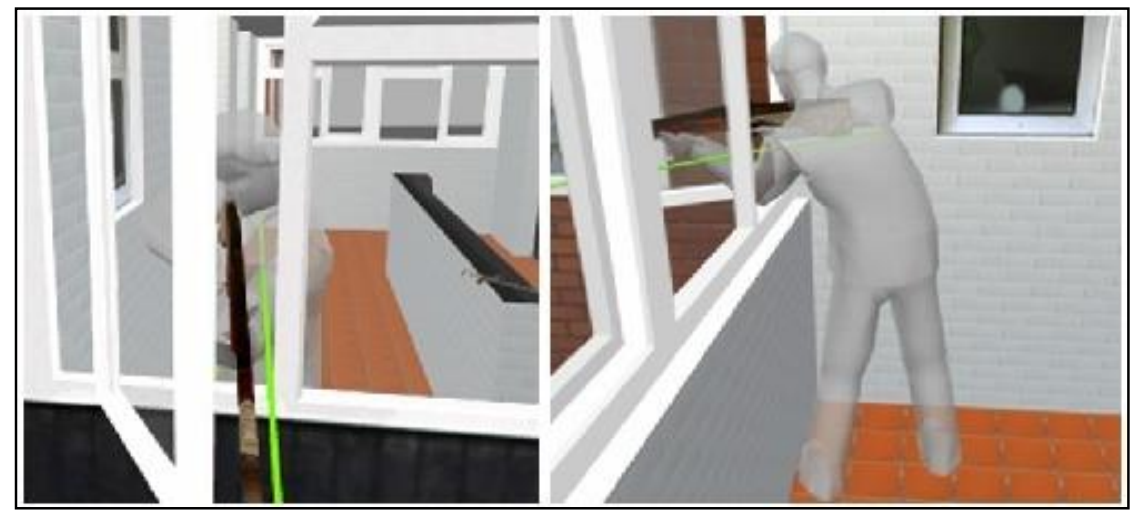

Figure 5 Two Images from a Forensic Animation of a Bullet Trajectory Reconstruction

Two recent, popular films demonstrate two distinct animation and representation styles. The first, Shrek® by Dreamworks Animation ${ }^{\circledR}$, relies on a cartoon-like, abstract approach to present its narrative. The second, Beowulf by Imagemovers ${ }^{\circledR}$, relies on a more realistic representational form. A number of researchers have noted an interesting observable fact relating to the realism in such animated imagery, where many viewers become "unnerved" by images of humans which are close to, but not quite real. This phenomenon 
(experienced by a number of viewers of the Beowulf movie) has become known as the "uncanny valley", because of the sharp dip seen in a graph of familiarity against the perception of reality (MacDorman, 2006).

However, the mixing of visual metaphors and modes may be potentially disorientating to some viewers. Combining abstract human representations in photo-realistic environments may provide an unnatural experience for the viewer. Fielder has commented on the way juries may be misled by the use of visual metaphors and abstract representations in forensic animations (Fielder, 2003).

In a forensic graphics context, many presentations based on video game technology which have been up till now been admitted into courtrooms have usually relied on fairly abstract representations. However, as technology develops, the development of increasingly photorealistic evidence reconstructions (such as the one shown in Figure 4) becomes ever more likely. Increasing use of the rendering of photorealistic components of the virtual model may lead to instances where the viewer is lulled into the previously discussed "seeing is believing" attitude, causing a potential relaxation of their critical faculties (Schofield, 2011; Speisel and Feigenson, 2009).

In summary, careful use of visual metaphors is essential. Thought needs to be given to each abstract data representation in the environment and how that will perceived by the potential audience. Experience and literature from disciplines such as psychology, cultural/critical theory, visual media, art history, education etc. can inform how abstract (and realist) representations are interpreted by the viewer. This in turn informs what the viewer actually takes away from a particular visual media experience, i.e., what they remember and understand from the evidence presented to them.

\subsection{Media Mode}

It is rare that one form of media will be sufficient to explain fully every facet of a complex process or case to a viewer. Many people see three-dimensional technology as a universal solution, and it has been "over-applied" or "misapplied" in many visualisation applications. It is important to choose an appropriate representation mode (photographs, text, video, graphics etc.) for the evidence that needs to be presented.

Additional forensic data may be included and displayed within any virtual environment; location-based statistical or analytical data may be displayed, calculation and test results may be presented in a visual format, and original documents and photographs can be linked from three-dimensional virtual objects (Schofield, 2007).

The first case in the UK known to utilise an interactive three-dimensional realtime virtual simulator to present evidence in court was the case of the murder 
of a motorcycle policeman in Birmingham, UK. A police officer, named Malcolm Walker, saw a stolen car shoot over a red light and followed the car but when the driver realised PC Walker was in pursuit, he stopped the vehicle, waited until the officer drew up alongside him and then deliberately drove into the officer's motorbike forcing him off the road. Officer Walker suffered multiple fatal injuries after being violently thrown from his bike (BBC News, 2002).

A large scale interactive virtual environment (shown in the left hand image of Figure 2) was created reconstructing the area over which the incident occurred (over a kilometer of roadway was modelled). It was specifically designed to allow the viewer to examine and identify all debris found at the scene of the incident, by using context-sensitive links to the digital photographic evidence (collected by the "scene of crime" officers) and to relevant forensic evidence (an example of a link to a scene photograph is shown in the right hand image of Figure 2). Over 300 individual items of evidence could be identified in the virtual reconstruction of the scene. This virtual simulation was used during the trial as a primary evidence display mechanism and helped to successfully convict the principal defendant and his associates of murder (West Midlands CPS, 2003).

The linking of "real" evidence to spatially-contextualised hotspots in a virtual environment has the potential to provide an effective mechanism to help the viewer understand the spatial relationship of the evidence. Such a multi-modal approach can be very effective, and different media may also be used as a device to help to retain attention of the viewer and thereby increase understanding (Ravet and Layte, 1997). An awareness of not only the impact of the particular media as it will be displayed but an appreciation of the context in which it will be experienced by the user is necessary. The pedagogical impact of transitions between media forms needs to be considered.

\subsection{Resolution}

How can one correlate the resolution of the virtual scene with that subjectively perceived by the real world viewer? In this instance resolution not only refers to screen image dimensions (pixel count) but also to the level of photorealism of the virtual environment created (Brooks, 1999). This also relates to the display mechanisms used, where a viewer watching a computer monitor does not have the same experience (depth of field, motion parallax, peripheral vision etc.) as a viewer watching a "live" event (Kanade et al., 1997; Tromp and Schofield, 2004).

Careful thought needs to be given to the enabling technology, the developer needs to know how the user will interact with any virtual simulation created. For example, the best mechanism could be to deliver spatially contextualised evidence visualisation to a user's Personal Digital Assistant (PDA) or mobile 
phone screen as they traverse the scene. Alternatively, a complex data set may be best viewed as a shared experience on a large screen in the courtroom.

Fowle et al. (2001) reported that one of Western Australia's first computer animations was used in a case where three men faced Judge Mary-Anne Yates in the Perth District Court in $17^{\text {th }}$ June 1997 (R v Marotta, Bull and King) for rape. Part of the defence case was a reconstruction of an event using video and computer graphics. The video was used to document how the measurements were taken of the scene. The computer graphics were used to show that it was impossible to re-enact the allegation without certain parameters being removed. These physical constraints can be seen in a still from the computer graphic animation created (Figure 6).

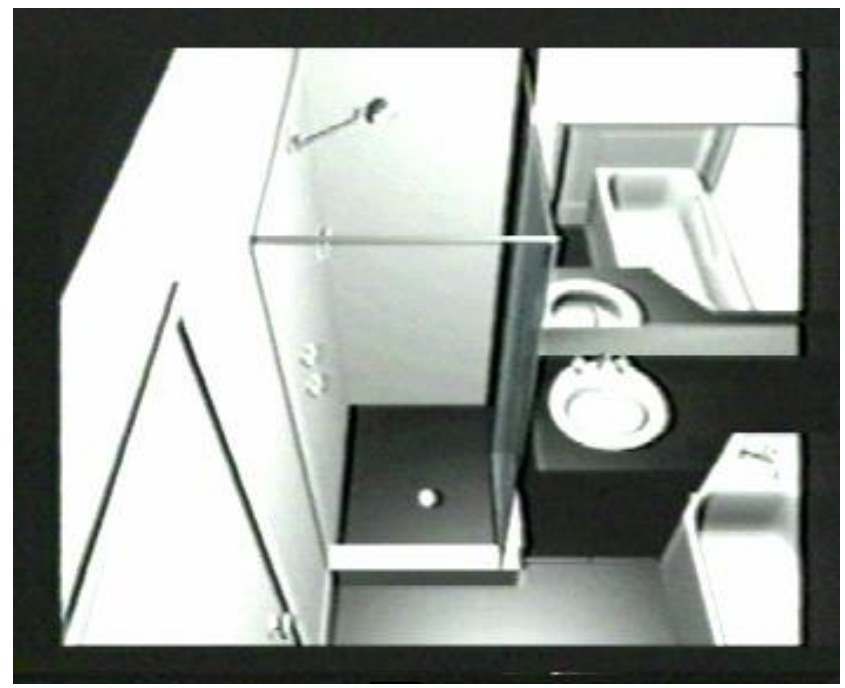

Figure 6 A Still from the R v Marotta, Bull and King Computer Generated Evidence

In this case evidence the crime scene was re-created as a three-dimensional virtual computer model and stills and animations showing the relevant spatial positions of the victim and the accused were prepared. For courtroom presentation, these images were displayed for the jury on television screens using standard video technology. The reasons for this included the ready availability of the video tape playback equipment in the courtroom and the familiarity of the jury with this mode of presentation.

Research has been undertaken comparing the impression effects of users watching videotaped footage (such as that shown in the case described above) with the viewing of 3D-computer animations on computer monitors. Socioemotional impressions have been assessed from both these presentation mechanisms based on standard adjective checklists. Only marginal differences have been found between the two presentation modes. In fact the data points to similarities in the impression ratings in both conditions, indicating that most of 
the relevant social information available to observers in the computer animations shown via the video recorders was also conveyed through the computer monitors (Bente et al., 2001; Schödl and Essa, 2002).

Developers need to be aware that three-dimensional virtual reconstructions are not a panacea solution to all visualisation requirements. They are not ideal for representing all potential evidence paradigms required by any particular case. Any developer should adopt a holistic, multi-modal visualisation approach using appropriate technology (whether that is text, photography, video, computer graphics etc.) for the particular material and evidential content.

\subsection{Accuracy}

Any forensic investigation begins with data collection: accuracy is crucial, because this data serves as the foundation for the evidence. At the scene, an investigator makes field measurements, may produce rough scene sketches, usually takes sets of photographs or video and then, at a later stage, drafts up accurate plans of the scene, analyses the forensic data and collates the information. The evidence taken from the scene will be analysed by experienced and suitably qualified investigators and, finally, the investigators will present their findings to a mixed audience of experts and lay people in a court (Burton et al., 2005).

Often a forensic investigator needs to present data to non-experts in the court; this is often a difficult task, fraught with problems and the potential for misunderstanding and misinterpretation. The first part of this paper explained how digital forensic data when collected and visualised may be easily readable by the trained expert but for the general public and untrained the images may mean very little.

Investigators face several problems when using the non-visual tools to analyse data. The main problem is information overload. The general public have difficulty in understanding large amounts of data and visualisation is particularly apt for addressing this issue. Hence, the use of visualisation is often seen as a necessary tool (Lowman, 2010).

The example shown in Figure 7 represents the number of times a known computer (collected as evidence in a particular case) was used to access the internet. This information is visualised using a heat-map, which is a graphical representation of data where the values taken by a variable in a twodimensional table are represented as colours, in this case shades of grey. The information presented is easy to read (since most people are familiar with "calendar-style" representations) and that it is clear to see that MondayWednesday between 05:00-09:59, and Saturday-Sunday 00:00-06:59 was the most common time the suspect was on the internet. Areas of peak activity are 
easy to identify and the viewer's eyes are drawn to these regions by the colouring even before they read the tabulated figures.

\begin{tabular}{|l|c|c|c|c|c|c|c|}
\hline & Mon & Tue & Wed & Thu & Fri & Sat & Sun \\
\hline $\begin{array}{l}\text { 00:00- } \\
00: 59\end{array}$ & & & & & & 44 & \\
\hline $\begin{array}{l}01: 00- \\
01: 59\end{array}$ & & & & & & 89 & 28 \\
\hline $\begin{array}{l}02: 00- \\
02: 59\end{array}$ & & & & & & 21 & 23 \\
\hline $\begin{array}{l}03: 00- \\
03: 59\end{array}$ & & & & & & 68 & 24 \\
\hline $\begin{array}{l}04: 00- \\
04: 59\end{array}$ & 5 & & & 10 & 138 & 39 & 25 \\
\hline $\begin{array}{l}05: 00- \\
05: 59\end{array}$ & 29 & 20 & 11 & 5 & 117 & 22 & 33 \\
\hline $\begin{array}{l}06: 00- \\
06: 59\end{array}$ & 45 & 25 & 33 & & & 3 & 17 \\
\hline $\begin{array}{l}07: 00- \\
07: 59\end{array}$ & 56 & 44 & 31 & & & & 7 \\
\hline $\begin{array}{l}08: 00- \\
08: 59\end{array}$ & 122 & 218 & 138 & & & & \\
\hline $\begin{array}{l}09: 00- \\
09: 59\end{array}$ & 180 & 300 & 300 & 221 & & & 31 \\
\hline $\begin{array}{l}10: 00- \\
10: 59 \ldots\end{array}$ & & & & & & & 48 \\
\hline
\end{tabular}

Figure 7 Internet Access Data Tabulated in an Easy to Read Manner

The technology used for collecting spatial data and measurements from a crime scene ranges from tape measures and traditional hand surveying tools (still used by many private accident investigators), to Electronic Distance Measurement (EDM) technology (used by many police organisations), to three-dimensional laser scanners (used by a number of large forensic organisations and government agencies). Collecting the data digitally allows for the automatic generation of three-dimensional coordinate information that will enable the data to be imported directly into a range of drafting and mapping software. These coordinates provide a reliable numerical data set for the creation of the geometry that is the foundation of any credible threedimensional computer model. If a virtual environment is created to a sufficient level of accuracy, then it may potentially be used to test hypotheses, such as to verify the location of a witness, especially where lines of sight around obstructions or hazards that are present in the environment may call into question the physical location of a witness (Noond et al., 2002; Schofield, 2011). 
Unlike the environment surrounding road a vehicle accident scene reconstruction where exact, surveyed measurements are usually available, pathology visualisations are often created based on descriptive post-mortem findings and approximate measurements. The use of anatomical computermodels allows the recreation of the dynamic event in which the wound or damage occurred. However, such a reconstruction of pathology evidence is, by its very nature, often dependant on the knowledge, expertise and opinion of medical experts (March et al., 2005).

As a further example of the issues involved in ensuring accuracy in a virtual crime scene, consider the problem of correlating the lighting in the virtual world with that available at the scene at the time of the incident. Is an approximation good enough? One could argue that in some cases this may not be crucial as it is only the line of sight which is under investigation, not the illumination of the objects (Walter et al., 1997).

It is very rare that light meters would be installed in a scene location, measuring the intensity of the illumination at a particular moment, thus allowing the designer of a virtual world to replicate that luminosity in their virtual environment. In many cases, one may argue that this is not an issue as the lighting may not be crucial to the viewing of the incident under consideration. However, when one considers how much effort is put into lighting a Hollywood movie to achieve a particular effect on the viewer, one begins to realise the enormous impact the lighting of the virtual environment may have (Schofield, 2011).

\subsection{Simulation}

It should never be forgotten that a virtual simulation, is by its very definition a "simulation" of reality. In the courtroom context, there is a need to understand the nature of the simulation and the veracity of the representation, i.e., how close is it to the original evidence from which it was derived (Fielder, 2003; Schofield, 2007; Speisel and Feigenson, 2009).

For example, the vehicle movement in a road traffic accident simulation may be based on the same equations as used by an accident reconstruction expert witness. However, questions that arise include: whether the simulation applies them in the same way; whether the simulation works to the same level of accuracy; whether the simulation make the same assumptions as the expert witness; and whether the visual representation provides a realistic and relevant portrayal of the simulation data (Noond et al., 2002).

The environment surrounding any particular scene that is to be reconstructed may be included within the virtual model. For example, a model may not only show the location of items or objects that form part of the evidence, but also the position of such items in relation to nearby objects, buildings or other 
environment features. Virtual objects within a three-dimensional virtual reconstruction can be modelled with varying degrees of accuracy to explain and visualise the certainty, believability and veracity of the information related to that object. For example, the trajectories of bullets are often displayed as cones or wedge shapes to show a range of possible positions of the weapon, instead of showing a single definitive line trajectory. Any of these items may be placed and animated within a chronology of events or a timeframe (Schofield, 2011).

In January 2008, three days of mock trials were held in the Supreme Court in Sydney, New South Wales, Australia as part of the Juries and Interactive Evidence (JIVE) research project. The trials involved the prosecution of a white supremacist terrorist bombing of Redfern train station in Sydney, Australia. A range of three-dimensional reconstructions and simulations were created from a single large scale virtual environment of the scene of the explosion (Figure 8). These simulations provided a re-enactment of the path the accused took on the train, the positioning of the tennis bag (presumed to have held the bomb) under the seat and the damage resulting from the subsequent explosion (Schofield, 2011; Tait et al., 2008).

Since this terrorist case was based on a hypothetical explosion, the reconstruction had to rely on simulation evidence from a forensic scientist. The specific debris patterns, the position and size of the crater and the damage to the train was all modelled based on information from the forensic scientist. If this case were a real case, then the train damage, crater size and debris locations would all have been measured and accurately partially positioned by the police or forensic survey team (Schofield, 2011; Tait, 2007).

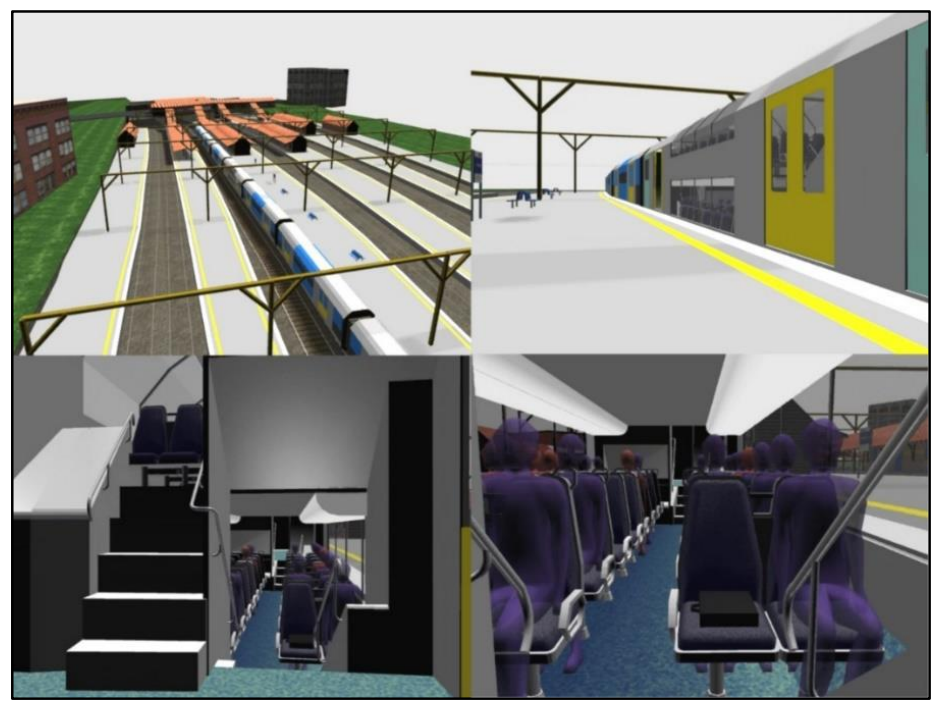

Figure 8 Images from the JIVE Project Terrorism Reconstruction 
It is important that the developers of these virtual environments have an understanding of the processes and events being simulated (whether this is vehicle movement, bullet trajectories or human anatomy). The developers must be aware of the veracity and realism of the simulation, i.e. the accuracy of the model. Also, it is important that the information needed to make decisions relating to the simulation is available and understandable as and when required.

Another import issue is the simulation of the flow of time within the virtual environment. When such technology is used to interact with a virtual environment, users are able to manipulate the timeline, take control and create their own narrative experience, as the simulations within these environments often contain media controls allowing the viewer to jump to, and play, the simulation from any point along the incident chronology (an example of this is the usage of the media player bar to jump between points in time; an example of which is shown in the shooting reconstruction in Figure 2). These media controls usually contain play, stop and pause buttons a display showing the current time within the simulation and a sliding time scale, similar to the interface of many commercial computer media players. This feature allows the user to view and assess the spatial position of objects in the world over time, while interactively controlling their own viewpoint and correlate this movement with witness testimony and other forensic evidence (Schofield, 2011).

However, the ability to move through time and along a chronology of events in a real-time virtual environment may be potentially disorientating too many viewers. Most members of the general public are used to linear narratives (for example, novels and films), and may struggle to follow multiple narrative threads when faced with such a non-linear approach, such as the usage of the media player bar to jump between points in time (Craven et al., 2001; Fielder, 2003). Developers should storyboard and flowchart the interactions in their environments and be aware of how the users can interact with the data and any possible interpretations that may result.

Many interactive virtual simulations have complicated navigation systems (often based on computer game style controls) which may add an extra layer of complexity to the data the user is trying to comprehend, rather than augmenting their understanding. Careful thought should be given to the options available to the user. If control is to be passed to the viewer then it may be better to restrict their movement and control in the virtual environment (for example between set waypoints) rather than allow them to get "lost" in the data or environment (Burton et al., 2005).

\subsection{Audio}

The integration of real-world audio evidence with a forensic animation has been used in the United States for many years. One of the first recorded 
applications of such a dual-modal forensic animation was the reconstruction of the Delta 191 plane crash in 1985. In the courtroom the animation was played alongside the audio from the cockpit voice recorder (Marcotte, 1989).

Research suggests that adding audio to a computer-generated visual can have a major impact on the level of engagement of the viewer, and hence may potentially affect their understanding and interpretation of the evidence viewed (Hendix et al., 1999). However, the integration of sound into the virtual world is often overlooked or added as an afterthought. Very few virtual developers are also qualified or competent sound engineers. Effective audio soundtracks can add new dimensions to the viewer's media experience.

\subsection{Other Issues: "Disneyfication" and Testing}

The emotive nature of the visual media produced can support a hypothesis put forward by a number of academics and lawyers that one of the possible dangers of using computer-generated visual evidence is that they can be "loaded" with emotive content that may have a prejudicial effect on the viewer. This effect has been discussed extensively by many researchers (Bailenson et al., 2006; Fielder, 2003; Girvan, 2001; O’Flaherty, 1996; Schofield, 2007; Speisel and Feigenson, 2009). This process of adding emotive content has been called "Disneying-up" the evidence (This phrase was first used by Galves (2000) in his paper Where the Not so Wild Things Are: Computers in the Courtroom, the Federal Rules of Evidence. The photorealistic rendering of components of the virtual model, may possibly lull the viewer into a "seeing-is-believing" attitude, causing a potential relaxation of their critical faculties (Sherwin, 2002; Speisel, 2006).

Finally, it seems like common sense, but any reconstruction developed should be tested before it is released out into the "real" courtroom environment. However, a number of these visualisation systems have often received limited user testing before their release (Schofield, 2006).

\section{CONCLUSIONS}

Whether one likes it or not, in the future the technology used to generate animated movies and computer games is going to be increasingly used to generate advanced visual evidence presentations in a number of courtroom jurisdictions around the world. This paper has, hopefully, been fairly positive about the future and the benefits that can arise through the introduction of this technology into our courtrooms.

However, there are a number of issues and concerns that arise through the use of forensic animations and virtual reconstructions to present evidence. There is a real risk with using these forms of visualization in courtrooms that the way in which they can be presented as evidence or expressed as a hypothesis can 
result in unfairness. These are not reasons in themselves for abandoning the use of this technology, but rather aspects that need to be investigated further and safeguards and guidelines put in place to avoid any possible misuse of this technology. A possible solution is to ensure that the true import of the evidence is explained and that juries and the general public are given correct understanding and explanations, ensuring that the problems associated with any assessment are noted. The qualifications and assumptions that led to the creation of the evidence must be explained and accompanied by appropriate warnings.

It is imperative that researchers and practitioners examine the implications of this technology, evaluate its potential advantages and disadvantages and assess its impact on those present in the courtroom. Once the impact of the visual media described in this paper is known and quantified then perhaps guidelines and rules can be developed governing the future use of the technology in courtrooms around the world.

\section{REFERENCES}

Bailenson, J. N., Blaschovich, J., Beall, A. C., and Noveck, B. (2006). Courtroom applications of virtual environments, immersive virtual environments and collaborative virtual environments. Law and Policy, 28(2): 249-270.

BBC News (2002, November 13). Driver bragged about killing policeman. Retrieved from http://news.bbc.co.uk/1/hi/england/2460325.stm on 10 December 2012.

BBC News (2005, March 21). Four jailed for New Year's killing. Retrieved from http://news.bbc.co.uk/2/hi/uk_news/england/west_midlands/4366177 on 10 December 2012.

Bente, G., Krämer, N. C., Petersen, A. and de Ruiter, J. P. (2001). Computer animated movement and person perception: Methodological advances in nonverbal behavior research. Journal of Nonverbal Behavior, 25(3): 151-166.

Britten, N. (2003). We know who killed the New Year's day party girls. The UK Daily Telegraph, 26 October 2003.

Brooks, F. P. (1999). What's real about virtual reality? IEEE Computer Graphics and Applications, 19(6): 16-27.

Bryce, J., and Rutter, J. (2002). Spectacle of the deathmatch: Character and narrative in first-person shooters. In G. King, and T. Krzywinska (eds), ScreenPlay: cinema/videogames/interfaces. London, England: Wallflower.

Burton, A., Schofield, D., and Goodwin, L. M. (2005). Gates of global perception: Forensic graphics for evidence presentation. Proceedings of ACM 
Symposium on Virtual Reality Software and Technology, 22 July 2005, Singapore.

Craven, M., Taylor, I., Drozd, A., Purbrick, I., Greenhalgh, C., and Benford, S. (2001). Exploiting interactivity, influence, space and time to explore non-linear drama in virtual worlds. Proceedings of the SIGCHI Conference on Human Factors in Computing Systems, 1-5 April 2001, Seattle, USA.

Fielder, B. (2003). Are your eyes deceiving you? The evidential crisis regarding the admissibility of computer-generated evidence. New York Law School Law Review, 48 (1\&2): 295-321.

Fowle, K., Steele, K., Annear, M., and Schofield, D. (2001). Recreating reality-Using computer generated forensic animations to reconstruct accident scenarios. Law Society of WA-Courting by Computer-Advocacy by Electronics in the IT Age, 28 March 2001, Perth, Western Australia.

Galves, F. (2000). Where the not so wild things are: Computers in the courtroom, the federal rules of evidence, and the need for institutional reform and more judicial acceptance. Harvard Journal of Law and Technology, 13(2): 161-302.

Girvan, R. (2001). An overview of the use of computer-generated displays in the courtroom. Web Journal of Current Legal Issues, 7(1).

Heintz, M. E. (2002). The digital divide and courtroom technology: Can David keep up with Goliath? Federal Communications Law Journal, 54: 567-589.

Henrix, C., Barfield, W., and Nystrom, K. (1999). A Conceptual Model of the Sense of Presence in Virtual Environments, Presence, Teleoperators and Virtual Environments, 8(2).

Kanade, T., Rander, P. J., and Narayanan, P. J. (1997). Virtualized reality: Constructing virtual worlds from scenes. IEEE Multimedia, 4(1): 34-47.

Lowman, S. (2010). Web History Visualisation for Forensic Investigations. MSc Forensic Informatics Dissertation, Department of Computer and Information Sciences. Glasgow, UK: University of Strathclyde.

MacDorman, K. F. (2006). Subjective ratings of robot video clips for human likeness, familiarity, and eeriness: An exploration of the uncanny valley. Proceedings of the ICCS/CogSci-2006 Long Symposium: Toward Social Mechanisms of Android Science, July 26th 2006, Vancouver, Canada.

March, J., Schofield, D., Evison, M., and Woodford, N. (2004). ThreeDimensional Computer Visualisation of Forensic Pathology Data. American Journal of Forensic Medicine and Pathology, 25(1): 60-70. 
Marcotte, P. (1989). Animated evidence: Delta 191 crash re-created through computer simulations at trial. Journal of the American Bar Association, 75: 5257.

Noond, J., Schofield, D., March, J., and Evison, M. (2002). Visualising the scene: Computer graphics and evidence presentation, science and justice. Journal of the UK Forensic Science Society, 42(2): 89-96.

O'Flaherty, D. (1996). Computer-generated displays in the courtroom: For better or worse? Web Journal of Current Legal Issues, 2(4).

Ravet, S., and Layte, M. (1997). Technology-Based Training. Houston, TX: Gulf Publishing Company.

Rogowitz, B., and Treinish, L. (1996). How Not to Lie with Vizualization. Computers in Physics, 10: 268-274.

Schnabel, M. A., and Kvan, T. (2003). Spatial Understanding in Immersive Environments. International Journal of Architectural Computing, 1(4): 435448.

Schödl, A., and Essa, I. (2002). Controlled animation of video sprites. Proceedings of the 2002 ACM SIGGRAPH/Eurographics Symposium on Computer Animation, 21-22 July 2002, San Antonio, Texas, USA.

Schofield, D. (2006). The Future of evidence: New applications of digital technologies, forensic science: Classroom to courtroom. Proceedings of $18^{\text {th }}$ International Symposium of the Forensic Sciences, 2-8 April 2006, Fremantle, Western Australia, 2006.

Schofield, D. (2007). Animating and interacting with graphical evidence: Bringing courtrooms to life with virtual reconstructions. Proceedings of IEEE Conference on Computer Graphics, Imaging and Visualisation, 14-16 August 2007, Bangkok, Thailand.

Schofield, D. (2009). Animating evidence: Computer game technology in the courtroom. Journal of Information, Law and Technology, 1. Retrieved from http://go.warwick.ac.uk/jilt/2009_1/schofield on 20 March 2012.

Schofield, D. (2011). Playing with evidence: Using video games in the courtroom. Journal of Entertainment Computing (Special Issue: Video Games as Research Instruments), 2(1): 47-58.

Schofield, D., and Mason, S. (2012). Using Graphical technology to present evidence. In S. Mason (Ed), Electronic evidence, $2^{\text {nd }}$ ed. London, England: Lexis-Nexis.

Schweitzer, N., and Saks, M., (2007). The CSI effect: Popular fiction about forensic science affects the public's expectations about real forensic science. Jurimetrics, Spring 2007: 357-64. 
Sherwin, R.K. (2002). When Law goes pop: The vanishing line between law and popular Culture. Chicago, IL: University of Chicago Press.

Spiesel, C. (2006). Reflections on reading: Words and pictures and law. International Journal of Law in Context, 2(3): 305-320.

Speisel, C. O., and Feigenson, N. (2009). Law on display: The digital transformation of legal persuasion and judgement. New York, NY: New York University Press.

Tait, D. (2007). Rethinking the role of the image in justice: Visual evidence and science in the trial process. Law, Probability and Risk, 6(1-4): 311-318.

Tait, D., Goodman-Delahunty, J., Schofield, D., and Jones, D. (2008). Evidence on the Holodeck: Jury responses to computer simulations. Proceedings of the Law and Technology Conference, Australian Institute of Judicial Administration, 25-27 June 2008, Sydney, Australia.

Tromp, J., and Schofield, D. (2004). Practical experiences of building virtual reality systems. Proceedings of Designing and Evaluating Virtual Reality Systems Symposium, 18 June 2004, Nottingham, UK.

Walter, B., Alppay, G., Lafortune, E. P., Fernandez, S., and Greenberg, D. P. (1997). Fitting virtual lights for non-diffuse walkthroughs. Proceedings of the 24th Annual Conference on Computer Graphics and Interactive Techniques, 38 August 1997, Los Angeles, USA.

Ware, C., and Osborne, S. (1990). Exploration and virtual camera control in virtual three dimensional environments. Proceedings of the 1990 Symposium on Interactive 3D Graphics, SIGGRAPH: ACM Special Interest Group on Computer Graphics and Interactive Techniques, Utah, USA.

West Midlands CPS (2003). Murder of a police officer: R v Nicolas Waters, Annual Report 2002-2003, Crown Prosecution Service (West Midlands), 9.

Wilson, J. R., Eastgate, R. M., and D'Cruz, M. (2002). Structured Development of virtual environments. Stanney, KM (ed), Handbook of virtual environments: Design, implementation and applications. New York, NY: Lawrence Erlbaum Associates, 353-378, 2002. 


\section{ABOUT THE AUTHORS}

Dr. Schofield $(\mathrm{PhD})$ is currently Director of Human Computer Interaction (Associate Professor) at the State University of New York (SUNY) Oswego, USA and an Adjunct Associate Professor of Digital Forensics in the School of Computer and Security Science at Edith Cowan University, Perth, Australia. Previous to this position he held the title of Associate Professor of Computer Games and Digital Media, in the School of Creative Media at RMIT University in Melbourne, Australia. In his earlier career, he was one of the managers of the internationally renowned Mixed Reality Lab (MRL) at the University of Nottingham in the UK.

Dr. Schofield has also been on the management board of both the Visual Learning Lab (a UK HEFCE centre of excellence) and the Learning Sciences Research Institute (UK). Dr. Schofield also remains a director and major shareholder of Aims Solutions Ltd., a UK based company providing computer graphics visualisation services and virtual reality based simulation training products to a wide range of public and private sector organisations.

Dr. Schofield has been involved in developing crime scene reconstructions using computer games/graphics technology for over 15 years. His research is specifically concerned with representation and understanding of visual information in the courtroom environment. The reconstructions he and his team create cover a wide range of forensic visualisation from computational fluid dynamics models to blood spatter patterns at crime scenes, from road traffic accident reconstruction to post-mortem pathology visualisation. Dr. Schofield is regularly used as an expert witness in courts all over the world and has worked on many high profile cases.

Dr. Schofield has been involved in forensic casework in the UK, Australia, USA, and Malaysia. A few years ago, he was responsible for the facial reconstruction of an Egyptian mummy for a documentary called Nefertiti Reserected on the Discovery Channel. For the last six years he has also been working on a major facial biometric project for the FBI (Federal Bureau of Investigation) in the USA.

Ken Fowle $(\mathrm{PhD})$ is currently the Head of School (Associate Professor), Computer and Security Science, at Edith Cowan University (ECU), Western Australian and an Adjunct Associate Professor at the University of Western Australia, Centre of Forensic Science (CFS). Prior to moving over to academia, Dr. Fowle was employed by the Department of Mines and Petroleum in the Investigation Branch.

Dr. Fowle's interest in visualisation and accident reconstruct started back in 1996, when seconded to the departments Mine Safety Branch to assist with developing computer applications for mining accident and incidents. This interest was further enhanced in 1999 when he was seconded to Central Tafe to 
establish a research and development group specifically for developing computer graphics for the resource sectors of Western Australia. During his time at Central Tafe, Dr. Fowle undertook a PhD with the University of Nottingham's AIM's research group.

In 2003, Dr. Fowle returned to the Department of Mines and Petroleum where he continued his research into visualisation and won funding from the WA Government, to continue research in the use of 3D environments for accident reconstruction. This research interest continues at ECU with collaboration with the WA Police Service, London Metropolitan Police, Northumbria University, State University of New York and local and national research groups such as IVEC, CFS and ECU's Security Research Institute.

Dr. Fowle is past president of the Australian and New Zealand Forensic Science Society and is still an active committee member, is a member of the International Association for Forensic Survey and Metrology, American Society for Industrial Security, Australian Computer Society, and the Australian Law Enforcement Forensic Surveying Working Group. 